\title{
QUALITY OF LIFE OF PATIENTS WITH TYPE 2 DIABETES IN RELATION TO METHOD OF TREATMENT
}

\author{
Marta Dudzińska ${ }^{1,2}$, Jerzy S. Tarach², Agnieszka Zwolak ${ }^{1,2,3}$, Joanna Malicka ${ }^{2}$, \\ Mariusz Kowalczyk $^{2}$, Jadwiga Daniluk ${ }^{3}$ \\ ${ }^{1}$ Chair of Internal Medicine and Department of Internal Medicine in Nursing, Medical University of Lublin \\ ${ }^{2}$ Department of Endocrinology, Medical University of Lublin \\ ${ }^{3}$ Department of Health, John Paul II State School of Higher Education in Biała Podlaska
}

Dudzińska M., Tarach J.S., Zwolak A., Malicka J., Kowalczyk M., Daniluk J. (2015), Quality of life of patients with type 2 diabetes in relation to method of treatment. Health Problems of Civilization, 4 (9), p. 26-31.

Summary: Inappropriate glycaemic control in type 2 diabetes leads to long-term complication and affects length of life. Intensification of treatment, involving insulin therapy is often delayed because of fear of negative influence on quality of life (QoL). Aims: evaluation of differences on QoL with type 2 diabetes patients in relation to method of current antidiabetic treatment, especially patients who are on the threshold of insulin therapy introduction. Methods: study involved 274 patients (mean 62.2 years, $55.8 \% \mathrm{~F}$ ) who were divided into 3 groups: patients treated with oral anti-diabetic agents (OAD group, $n=111$ ), patients, for whom insulin was introduced (Intensification group, $n=68$ ) and patients treated with insulin (Insulin group, n=95). QoL was measured with questionnaires: EQ-5D, DQL-BCI and DSC-R. Results: There were no statistically significant differences in EQ-5D indices among studied patients (OAD group-0.82, Intensification group-0.78, Insulin group-0.75). EQ-VAS among patients switched to insulin therapy was lower than in OAD group (52.7 and 59.3, respectively, $\mathrm{p}=0.004$ ). The differences in DQL-BCI scores among all groups of patients were statistically insignificant (scores: OAD group-56.7, Intensification group-54.8, Insulin group-51.7). DSC-R score in Intensification group was higher than among OAD group (30.9 and 25.3, respectively, $p=0,08)$. Patients switched to insulin therapy manifested the highest level of hyperglycemia-related burden and the lowest treatment satisfaction. Conclusions: patients whose treatment was intensified reported their QoL as lower than the patients treated with OAD, however there was no significant difference found in respect of QoL between patients from the latter group and patients already treated with insulin.

Keywords: type 2 diabetes, quality of life, insulin therapy

\section{Introduction}

The primary aim of diabetes treatment is the avoidance of complications through striving for optimal metabolic control levels, it however cannot be the only aim we should focus on. According to St. Vincent Declaration (1989) physicians should put more attention on psycho-social aspects of diabetes treatment, which include also quality of life (QoL). While treating diabetes it should be essential to reach a compromise between both rigorous glycaemic control and possibly the smallest harm to quality of patient's life. This problem is especially important in stage of insulin therapy introduction in course of type 2 diabetes, when physicians as well as patients often afraid deterioration of QoL. This stadium of diabetes should be closely examined with special attention to QoL, in order to help patients more effectively. Despite the fact that there is a progressing trend in the quality of life research, the literature concerning assessment of this problem in Poland and Eastern Europe is also very limited, especially as concern studies provided in everyday clinical practice. These facts serve therefore as an incentive for further studies in this direction.

\footnotetext{
Address for correspondence: Marta Dudzińska, Chair of Internal Medicine and Department of Internal Medicine in Nursing, Medical University of Lublin, Jaczewskiego 8, 20-954 Lublin, phone: 8174258 25, e-mail: m.dudzinska1@o2.pl

Tables: 2 Figures: 0 References: 23 Full-text PDF www.hpc.edu.pl Copyright (c) Pope John Paul II State School of Higher Education in Biała Podlaska, Sidorska 95/97, 21-500 Biała Podlaska Indexation: Index Copernicus, AGRO, ProQuest, Polish Medical Bibliography, Polish Ministry of Science and Higher Education. This is an open-access article distributed under the terms of the Creative Common Attribution Non-commercial license (http://creativecommons.org/licenses/by-nc/3.0), which permits use, distribution and reproduction in any medium, provided the original works is properly cited, the use is non-commercial and is otherwise in compliance with the license.
} 


\section{Aim of this study}

The aim of this study was to evaluate the quality of life of patients, who are on the threshold of insulin therapy introduction. In order to achieve this aim it was decided to compare the obtained results with groups of patients, who were treated with oral drugs or insulin.

\section{Patients and Methods}

Study involved 274 patients with type 2 diabetes, hospitalized in the Department of Endocrinology, Public Hospital No 4, Lublin or treated at Diabetes Outpatients Clinic or District Diabetes Outpatient Clinic in Lublin, Poland. All patients were divided into 3 groups according to the type of their therapy: patient treated by oral anti-diabetic drugs (OAD group): $n=111$ (63F), Intensification group: 68 patients whose therapy was intensified by the insulin therapy introduction $(38 \mathrm{~F}$ ) and Insulin group: 95 patients treated with insulin (53F). General inclusion criteria: type 2 diabetes duration of $\geq 6$ months, patient's physical and psychical health condition allowing independent questionnaire filling, patient's agreement. Detailed criteria: the minimum of 6 months treatment with oral anti-diabetic drugs (OAD group) or the minimum of 6 months treatment with insulin (Insulin group) or a treatment with oral medications and a decision of attending physician's to start the insulin therapy (Intensification group). Clinical and QoL assessment of patient from Intensification group was undertaken just before introduction of insulin therapy. Patients qualified for a temporary insulin administration e.g. during the periprocedural period were not included in the study. All patients before participating in the study gave written informed consent in compliance with principles of Declaration of Helsinki. The study had an observatory character, thus the researchers did not interfere with the diagnostic or therapeutic process. Clinical data and valuation of metabolic control was obtained from patient' medical files and described elsewhere (Dudzińska et al. 2011, Dudzińska et al. 2011).

For purposes of the study the researcher applied the diagnostic survey method by using a questionnaire for general QoL EQ-5D, as well as two diabetes-specific questionnaires: DQL-BCI and DSC-R.

The generic quality of life EQ-5D questionnaire consists of two parts: an EQ-5D descriptive system (scored as EQ-5D index- range from - 0.461 to 1,1 is perfect QoL) and an EQ visual analog scale (EQ-VAS, range $0-100,100$ is perfect health) (Szende et al. 2004, Golicki et al. 2010). The EQ-5D index results were calculated on the basis of Polish value set created by Golicki et al. (2010). Diabetes Quality of Life-Brief Clinical Inventory (DQL-BCI) is applied for the QoL assessment in cases of diabetes type 1 and 2 (Burroughs 2004) created on the basis of one of the most commonly used tools specific for diabetes- DQOL (Jacobson 1994). The total score is ranged 15 to 75 (75 is the best QoL) (Burroughs 2006).

The DQL-BCI was standardized in English (US) and has never been used in Poland. The questionnaire's author gave his consent for its application and translation into Polish for use of the study, psychometric evaluation of the Polish version of DQL-BCI was described elsewhere (Dudzińska et al. 2014). To the best knowledge of authors the present study is first to use DQL-BCI in Europe and in Poland.

The Diabetes Symptom Checklist-Revised (DSC-R) is standardized, disease-specific questionnaire used for assessment QoL, especially in order to subjectively assess the frequency and strength of diabetes symptoms and their changes as a consequence of treatment among type 2 diabetes patients (Grootenhuis et al. 1994, Arbuckle et al.2009). The DSC-R consists of 34 items grouped into eight symptom subscales. Received scores are then transformed to a $0-100$ score to obtain the DSC-R total score. The same transformation is applied to the DSC-R subscales. The higher score means the higher nuisance level and thus the worse QoL. The questionnaire was obtained in the Polish version (www.mapi-trust.org).

\section{Statistical analysis}

The values of the considered parameters were measured in the nominal scale, characterised by means of multiplicity and proportion, as well as in the quotient scale, which referred to mean values and standard deviation with its variance. In order to identify any differences or relationships a $\chi$-square test was conducted (for the size $<5$ Yates correction for continuity was applied). The Kruskal-Wallis $\mathrm{H}$ test and multiple post-hoc comparison tests were used to compare more than two groups. A $5 \%$ inference error and a significance level of $\mathrm{p}<0.05$ were assumed, pointing to the existence of statistically significant differences or relationships. The statistical analysis was carried out using STATISTICA v. 8.0 software (StatSoft, Poland). 


\section{Results}

The characteristics of the population examined in the study are shown in the table 1.

Table 1. Population characteristics

\begin{tabular}{|c|c|c|c|c|}
\hline variable & $\begin{array}{l}\text { OAD group } \\
n=111\end{array}$ & $\begin{array}{c}\text { Intensification } \\
\text { group } \\
n=68\end{array}$ & $\begin{array}{l}\text { Insulin group } \\
\quad n=95\end{array}$ & p-value ${ }^{1}$ \\
\hline age $^{2}$ (years) & $61.8 \pm 10.4$ & $63.1 \pm 10.1$ & $62.1 \pm 9.0$ & 0.69 \\
\hline $\begin{array}{ll}\text { women } & \mathrm{n}(\%) \\
\text { men } & \mathrm{n}(\%)\end{array}$ & $\begin{array}{l}63(56.8) \\
48(43.2)\end{array}$ & $\begin{array}{l}38(55.9) \\
30(44.1)\end{array}$ & $\begin{array}{l}53(55.8) \\
42(44.2)\end{array}$ & 0.98 \\
\hline $\begin{array}{c}\begin{array}{c}\text { duration of diabetes } \\
\text { (years) }\end{array} \\
\end{array}$ & $7.3 \pm 5.9$ & $10.5 \pm 6.4$ & $14.2 \pm 7.4$ & 0.001 \\
\hline $\begin{array}{l}\mathrm{HbA1c}^{2}(\%) \\
(\mathrm{mmol} / \mathrm{mol})\end{array}$ & $\begin{array}{c}6.7 \pm 1.1 \\
(50 \pm 12)\end{array}$ & $\begin{array}{l}8.2 \pm 1.7 \\
(67 \pm 19)\end{array}$ & $\begin{array}{c}7.9 \pm 1.5 \\
(63 \pm 16)\end{array}$ & 0.001 \\
\hline $\begin{array}{c}\text { Coronary heart disease } \mathbf{n}(\%) \\
\text { Retinopathy } \mathbf{n}(\%) \\
\text { Neuropathy } \mathbf{n}(\%) \\
\text { Nephropathy } \mathbf{n}(\%)\end{array}$ & $\begin{array}{c}38(34.2) \\
10(9.0) \\
1(0.9) \\
3(2.7)\end{array}$ & $\begin{array}{c}24(35.3) \\
6(8.8) \\
4(5.9) \\
6(8.8)\end{array}$ & $\begin{array}{c}45(47.4) \\
33(34.7) \\
15(15.8) \\
6(6.3)\end{array}$ & $\begin{array}{c}0.1 \\
\mathbf{0 . 0 0 1} \\
\mathbf{0 . 0 0 1} \\
0.2\end{array}$ \\
\hline
\end{tabular}

${ }^{1}$ Kruscal-Wallis test $\mathrm{H}$ for age, diabetes duration and HbA1c, $\chi^{2}$-test for other variables for differences between groups,

${ }^{2}$ mean $\pm \mathrm{SD}$,

Source: own elaboration.

Concerning EQ-5D dimensions the general QoL assessment (EQ-5D index) among patients for whom the therapy had been intensified tend to be poorer than patients treated with OAD, and slightly better than patients treated with insulin, but these differences failed to reach statistical significance (tab. 2).

Table 2. Quality of life scores

\begin{tabular}{|c|c|c|c|}
\hline Variable & $\begin{array}{c}\text { OAD } \\
\text { group } \\
n=111\end{array}$ & $\begin{array}{l}\text { Intensification group } \\
\qquad n=68\end{array}$ & $\begin{array}{c}\text { Insulin } \\
\text { group } \\
n=95\end{array}$ \\
\hline EQ-5D index ${ }^{1}$ & $0.82 \pm 0.11$ & $0.78 \pm 0.14$ & $0.75 \pm 0.16$ \\
\hline EQ-VAS $^{1}$ & $59.3 \pm 13.3$ & $52.7 \pm 15.2$ & $51.2 \pm 14.5$ \\
\hline DQL-BCI $^{1}$ & $56.7 \pm 7.7$ & $54.8 \pm 6.9$ & $51.7 \pm 8.1$ \\
\hline DSC-R total $^{2}$ & $25.3 \pm 13.6$ & $30.9 \pm 15$ & $33.3 \pm 15.7$ \\
\hline \multicolumn{4}{|l|}{ DSC-R domains: } \\
\hline Psychological fatigue $^{1}$ & $37.4 \pm 20.5$ & $42.1 \pm 23.0$ & $42.5 \pm 21.1$ \\
\hline Psychological cognitive $^{1}$ & $23.9 \pm 18.7$ & $26.6 \pm 20.8$ & $24.6 \pm 19.7$ \\
\hline Neuropatic pain $^{1}$ & $23.6 \pm 20.1$ & $31.2 \pm 24.2$ & $36.3 \pm 25.3$ \\
\hline Neuropathic sensoric $^{1}$ & $21.7 \pm 15.6$ & $26.3 \pm 21.9$ & $35.2 \pm 21.9$ \\
\hline Cardiovascular $^{1}$ & $28.0 \pm 20.8$ & $34.0 \pm 23.14$ & $33.3 \pm 21.7$ \\
\hline Ophtalmologic ${ }^{1}$ & $23.0 \pm 18.1$ & $26.3 \pm 22.8$ & $32.0 \pm 22.8$ \\
\hline Hypoglycemic ${ }^{1}$ & $17.7 \pm 17.9$ & $15.9 \pm 16.5$ & $23.7 \pm 22.7$ \\
\hline Hyperglycemic ${ }^{1}$ & $27.7 \pm 23.1$ & $44.6 \pm 25.1$ & $35.6 \pm 23.9$ \\
\hline
\end{tabular}

${ }^{1}$ mean \pm SD

Source: own elaboration. 
Subjective health condition assessment (EQ-VAS) of patients from this group marked significantly lower values than patients treated with $\operatorname{OAD}(\mathrm{p}=0.01)$. It is also worth mentioning that patients treated with insulin assessed their QoL lower than patients treated with oral drug in respect of both EQ-5D index $(\mathrm{p}=0.01)$ and EQ$\operatorname{VAS}(\mathrm{p}<0.001)$.

The mean total scores of DQL-BCI were described on tab.2. We observe a tendency of poorer QoL assessment of patients from Intensification group than of those treated with OAD and at the same time slightly better than of patients treated with insulin, but these differences failed to reach statistical significance. It is worth to stress, that mean score of patients treated with insulin was noticeably lower than those treated with $0 A D(p<0.001)$, which suggests lower QoL in the first of mentioned group.

Chosen questions from the DQL-BCI underwent detailed analysis. The patients from the Intensification group were the most dissatisfied with current diabetes treatment (19.1\%) when compared to patients from other groups (Insulin group-15.8\%, OAD group-6.30\%, p<0.001). It is also worth mentioning that the greatest burden with the diabetes related pain was observed among patients treated with insulin (57.9\%), in comparison to other patients (OAD group-15.3\%, Intensification group-8.8\%, $\mathrm{p}<0.001$ ).

Data obtained by use of DSC-R as a total score and particular subscores are presented in table 2. Patients switched from OAD to insulin therapy had slightly lower QoL than patients treated with $\operatorname{OAD}(\mathrm{p}=0.08)$, but there are no statistically important differences between the Intensification group and the Insulin group. It is worth mentioning that noticeably higher QoL measured with DSC-R total score was observed among patients treated with OAD in contrast to patients treated with insulin ( $\mathrm{p}<0.001)$.

Analysis of certain subdomains, especially "hypergycemia", confirmed higher scores among patients who underwent the therapy intensification than patients from the OAD group $(p<0.001)$ and the insulin treated group $(p=0.05)$. The ophthalmologic symptoms were more frequent among patients treated with insulin than among patients treated with OAD ( $\mathrm{p}=0.01)$. Similarly higher values in subdomain "neuropathic sensoric" were declared by insulin treated patients than by both OAD treated patients $(\mathrm{p}<0.001)$ and patients by whom therapy was intensified $(\mathrm{p}=0.01)$. Also within the Insulin group the score in subdomain "neurology-pain" was higher than in the case of patients from the OAD group $(\mathrm{p}<0.001)$.

\section{Discussion}

The analysis of data obtained by the use of all applied questionnaires shows the tendency to lower quality o life assessment among patients whose treatment was intensified by insulin therapy introduction in comparison to the patients treated with OAD. When comparing results of patients from the group switched to insulin and from the group treated with insulin in the case of all applied questionnaires no significant differences were found, although the level of hyperglycemia-related burden was slightly higher in the former group. Additionally QoL of patients treated with OAD was noticeably higher than those treated with insulin. Lower QoL among insulin treated patients point to a heavier burden with diabetes symptoms, which results from a longer duration of the disease and more advanced complications among these patients.

Three different, complementary QoL tools were used in the study. DQL-BCI for the purpose of this study was translated and adapted to the Polish conditions. According to author's knowledge this is the first use of this questionnaire in Poland and Europe.

The limitation for this research was a relatively small number of patients, who took part in the research, particularly when it comes to patients whose treatment were intensified. This fact encourages authors for further study in this direction.

There are many studies proving that QoL of patients treated with OAD is better than of the insulin treated group. These observations refer to both general QoL (Jacobson et al.1994, Koopmanschap 2002, Pufal et al. 2004), and measured by diabetes-specific tools (Jacobson et al.1994, Grootenhuis et al. 1994, Davis et al.2001). It is however obvious that the manner of treatment is not the only reason for that situation and rather it is secondary to many factors, such as the disease advancement (Pufal et al. 2004, Solli et al. 2010, Sparring et al. 2013) or intensity of complication (Koopmanschap 2002, Solli et al. 2010, Lewko et al. 2007). Nonetheless there are researches who claim that insulin therapy as such is an independent factor contributing to QoL worsening (Davis et al. 2001). However a UKPDS study proved, that insulin therapy was not connected with the deterioration of QoL (UKPDS37 1999). According to other researchers, patients on insulin therapy described their QoL as better than OAD treated patients, as they argue, patients from the former group are more able for adaptation (Ptasiński et al. 2008).

The relationship between a metabolic control and QoL was discussed by many authors, many of them acknowledge the correlation between lower HbA1c values and higher QoL (Testa et al. 1998). Other studies 
emphasize the significance of hyperglycemia occurrences, which cause feeling of fatigue, sleep problems, frequent infections and generally connected with inconveniences, for QoL (Kleefstra et al. 2005). In our study patients treated with OAD declared significantly better general overall QoL as well as diabetes-related QoL than those treated with insulin. Considering the factors that influence the QoL (longer disease duration, higher intensity of complications, a worse metabolic control in the Insulin group than in the OAD group) these results are not surprising.

This study devoted special attention to the group of patients whose treatment had been intensified. These patients declared worse QoL than those treated with OAD. One of reasons for this situation is longer duration of the disease among patients from the discussed group but the main culprit here is most probably a worse diabetes control, especially the severity of symptoms of hyperglycemia, which is considered to be independent QoL lowering factor (Kleefstra et al. 2005). Similar findings were described by other authors (Piberinik-Okanović 1998). Patients, as well as physicians, are often afraid of lower QoL after the insulin therapy introduction (necessity of injections, fear of being dependent on others, higher risk of hypoglycemia). In many cases it leads to the postponement of insulin therapy administration when there is an inadequate glycemic control. As this study yielded - the QoL of these patients is not different from that of patients treated already with insulin (no differences in respect of both general and diabetes-specific questionnaires), apart from higher hyperglycaemiarelated burden among patients from Intensification group. Additionally, considering the fact, that satisfaction with treatment in this group of patients was lower than that of the insulin treated patients, the fear of insulin therapy introduction and QoL worsening as a result of that seems unreasonable.

\section{Conclusions}

1. The patients whose treatment was intensified described their QoL as lower than patients treated with oral hypoglycaemic drugs, but there was no difference between QoL former group and patients treated with insulin.

2. Higher severity of hyperglycemia symptoms and a lower degree of satisfaction with treatment in the group undergoing intensification therapy compared with those already treated with insulin should encourage the early implementation of insulin therapy.

3. QoL of the patients treated with OAD was better than of those, treated with insulin, which results from longer diabetes duration and complications, rather than the way of treatment.

\section{Acknowledgement}

Conflict of interest: none declared

Abbreviations: QoL- Quality of Life, DQL-BCI- Diabetes Quality of Life-Brief Clinical Inventory, DSC-RDiabetes Symptom Checklist-Revised, OAD-oral anti-diabetic drugs, HbA1 - glycated haemoglobin

\section{References:}

1. Arbuckle R.A., Humphrey L., Vardeva K., Arondekar B., Danten-Viala M., Scott J.A., Snoek FJ. (2009), Psychometric Evaluation of the Diabetes Symptom Checklist-Revised (DSC-R)-A Measure of Symptom Distress. Value in Health, 12: 1168-1175.

2. Burroughs T.E., Desikan R., Waterman B.M., Gilin D., McGill J. (2004), Development and Validation of the Diabetes Quality of Life Brief Clinical Inventory. Diabetes Spectrum, 17: 41-49.

3. Burroughs T.E. (2006), Development and Validation of Diabetes Quality of Life- Brief Clinical Inventory. Administrator's Manual, v3.2. Saint Louis University Center for Outcomes Research, Saint Louis.

4. Davis T.M., Clifford R.M., Davis W.A. (2001), Effect of insulin therapy on quality of life in type 2 diabetes mellitus: The Fremantle Diabetes Study. Diabetes Research and Clinical Practice, 52: 63-71.

5. Diabetes Care and Research in Europe: the St Vincent Declaration (1989), $1^{\text {st }}$ Meeting of St Vincent Declaration Diabetes Action Programme, St Vincent, Italy.

6. Dudzińska M., Tarach J.S., Matuszek B., Kowalczyk M., Wdowiak-Barton B., Kiszczak-Bochyńska E., Nowakowski A. (2011), Evaluation of metabolic control in patients with type 2 diabetes depending on the type of hypoglycemic treatment. Experimental and Clinical Diabetology, 11: 1-7.

7. Dudzińska M., Tarach J.S., Malicka J., Kurowska M., Kowalczyk M., Nowakowski A. (2011), Why, when and how insulin therapy is being started for patients with type 2 diabetes treated with oral medications: an observation 
study. Experimental and Clinical Diabetology, 11: 45-50.

8. Dudzińska M., Tarach J.S., Burroughs T.E., Zwolak A., Matuszek B., Smoleń A., Nowakowski A. (2014), Validation of the Polish version of Diabetes Quality of Life - Brief Clinical Inventory (DQL-BCI) among patients with type 2 diabetes. Archives of Medical Science (in press).

9. Golicki D., Jakubczyk M., Niewada M., Wrona W., Busschbach J.J. (2010), Valuation of EQ-5D health states in Poland: first TTO-based social value set in Central and Eastern Europe. Value Health, 13: 289-297.

10. Grootenhuis P.A., Snoek F.J., Heine R.J., Bouter L.M. (1994), Development of type 2 Diabetes Symptom Checklist: a Measure of Symptom Severity. Diabetic Medicine, 11: 253-261.

11. Jacobson A.M., De Groot M., Samson J.A. (1994), The evaluation of two measures of quality of life in patients with type I and II diabetes. Diabetes Care, 17: 267-274.

12. Kleefstra N., Ubink-Veltmaat L.J., Houweling S.T., Groenier K.H., Meyboom-de Jong B., Bilo H.J. (2005), Crosssectional relationship between glycaemic control, hyperglycaemic symptoms and quality of life in type 2 diabetes (ZODIAC-2). Neth J Med. 63: 215-221.

13. Koopmanschap M. (2002), Coping with type II diabetes: the patient's perspective. Diabetologia, 45:S18-22.

14. Lewko J., Polityńska B., Kochanowicz J., Zarzycki W., Okruszko A., Sierakowska M., Jankowiak B., Górska M., Krajewska-Kułak E., Kowalczuk K. (2007), Quality of life and its relationship to the degree of illness acceptance in patients with diabetes and peripheral diabetic neuropathy. Advances in Medical Sciences, 52(Suppl.1): 144146.

15. Mapi Research Trust: www.mapi-trust.org (accessed: 05.08.2014).

16. Piberinik-Okanović M., Szabo S., Metelko Z. (1998), Quality of life following a change in therapy for diabetes mellitus. Pharmacoeconomics, 14:201-204.

17. Ptasiński A., Pączek L. (2008), Influence of diabetes on quality oflife- assessment with use of ADDQL questionnaire in general practice. Medycyna Metaboliczna, 12: 45-48.

18. Pufal J., Gierach M., Pufal M., Bronisz A., Kiełbasa L., Junik R. (2004), The influence of socio-demographic and clinical factors on quality of life of patients with type 2 diabetes. Experimental and Clinical Diabetology, 4:137143.

19. Solli O., Stavem K., Kristiansen I.S. (2010), Health-related quality of life in diabetes: The associations of complications with EQ-5D scores. Health Qual Life Outcomes, 4; 8-18.

20. Sparring V., Nyström L., Wahlström R., Jonsson P.M., Ostman J., Burström K. (2013), Diabetes duration and health-related quality of life in individuals with onset of diabetes in the age group 15-34 years - a Swedish population-based study using EQ-5D. BMC Public Health, 13:377.

21. Szende A., Williams A. (2004), Measuring Self-Reported Population Health: An International Perspective based on EQ-5D. EuroQol Group. SpringMEDPublishing.

22. Testa M.A., Simonson D.C. (1998), Health economic benefits and quality of life during improved glycemic control in patients with type 2 diabetes mellitus: a randomized, controlled double blind trial. JAMA, 280: 1490-1496.

23. U.K. Prospective Diabetes Study Group: Quality of life type 2 diabetic patients is affected by complications but not by intensive polices to improve blood glucose or blood pressure control (UKPDS37). (1999) Diabetes Care, 22: 1125-1136.

Submitted: 28.07.2014

Accepted: 08.07.2015 